\title{
A policy for hypertension
}

Sir:

In a leading article (British Heart fournal, 1975, 37,893 ) you say disapprovingly that it has been widely inferred that 'substantial reductions in mortality and morbidity can be expected from effective treatment of mildly raised blood-pressure (diastolic $95-110 \mathrm{mmHg}$ )' and you cite a Lancet leader as source of this quoted passage. In the original the passage was prefaced by a ponderous but unmistakable qualification: 'Although the case is far from proven, the indications are that . . $\therefore$ Unhappily this qualification does not appear, even with leavening, in your own article. Elsewhere you cite our leader as suggesting that 'all those with a diastolic pressure of $95 \mathrm{mmHg}$ or over should be on hypertensive therapy ... $\therefore$ We made no such suggestion. In our editorial (entitled Home Bloodpressure Recording) we said that this group may comprise 15 to 20 per cent of the adult population, 'and if it is true that all these patients are at increased risk and would benefit from therapy then an enormous work-load will be generated.' This is a far cry from a general summons to the dispensary. As we said on 11 October (Shall I Treat Mild Hypertension?), 'to embark on widespread treatment, without solid evidence of efficacy, might be costly folly'.

Ian Douglas-Wilson,

Editor,

The Lancet,

7 Adam Street,

London WC2N 6AD.
This letter was shown to Dr. Short who replies as follows:

Sir:

I am grateful to the Editor of the Lancet for clarifying his attitude to the treatment of mildly raised blood pressure. When I first read the Leading Article in the Lancet $(1975,1,259)$ it seemed that it would be widely interpreted as enencouraging the treatment of mild hypertensiona course of action which in my view is entirely unjustified. Moreover, I consider that it was misleading to cite the Framingham study in support of this attitude, since the Framingham study dealt with the risks of hypertension and not with the benefits of treatment. I criticized the Leading Article at the time it appeared (Lancet, 1975, 1, 531) and this criticism has, to my knowledge, never been answered in that periodical.

On rereading the Leading Article with the Editor's observations in mind, I still feel it gives the impression that antihypertensive treatment should be seriously considered in anyone with a diastolic blood pressure of $95 \mathrm{mmHg}(12.6 \mathrm{kPa})$ or more. I am glad to be assured that this is not the view of the Editor.

David Short,
Cardiac Department,
Aberdeen Royal Infirmary,
Foresterhill,
Aberdeen.

